
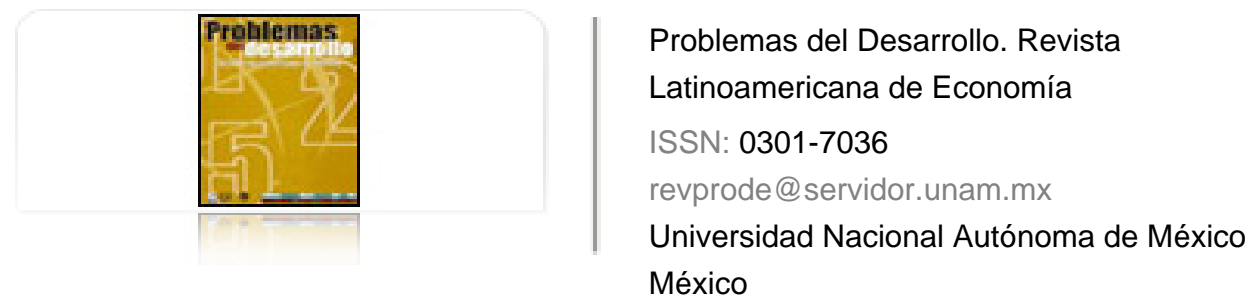

Cruz, Moritz; Lapa, Javier

Crisis y recuperación económica: el papel de la política fiscal

Problemas del Desarrollo. Revista Latinoamericana de Economía, vol. 43, núm. 168, enero-marzo, 2012, pp. 95-116

Universidad Nacional Autónoma de México

Distrito Federal, México

Disponible en: http://www.redalyc.org/articulo.oa?id=11822277005

- Cómo citar el artículo

- Número completo

- Más información del artículo

Página de la revista en redalyc.org

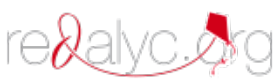

Sistema de Información Científica

Red de Revistas Científicas de América Latina, el Caribe, España y Portugal Proyecto académico sin fines de lucro, desarrollado bajo la iniciativa de acceso abierto 
Revista Problemas del Desarrollo, 168 (43), enero-marzo 2012

\title{
CRISIS Y RECUPERACIÓN ECONÓMICA: EL PAPEL DE LA POLÍTICA FISCAL
}

\author{
Moritz Cruz* y Javier Lapa**
}

Fecha de recepción: 9 de junio de 2011. Fecha de aceptación: 22 de septiembre de 2011.

\section{RESUMEN}

Desarrollamos un análisis comparativo de cinco economías que experimentaron crisis financieras recientemente (México 1994, Corea del Sur 1997, Rusia 1998, Brasil 1998 y Argentina 2001), con el fin de identificar el papel que la política económica jugó durante la crisis y el posterior proceso de recuperación económica. Nuestro análisis indica que únicamente México enfrentó y mantuvo su política económica, incluida la fiscal, sujeta a las restricciones del modelo económico que originó la crisis. Aunque Brasil hizo lo mismo para enfrentar la crisis, durante su proceso de recuperación rompió con dicha restricción. Finalmente, Argentina, Corea y Rusia se caracterizaron por romper desde la misma crisis, aunque en diferentes grados, con la restricción de política económica, postura que se ha mantenido desde entonces.

Palabras clave: crisis financiera, política económica, política fiscal, recuperación económica.

\section{CRISIS AND ECONOMIC RECOVERY: THE ROLE OF FISCAL POLICY}

\begin{abstract}
We develop a comparative analysis of five economies that recently went through financial crises (Mexico 1994, South Korea 1997, Russia 1998, Brazil 1998 and Argentina 2001), in order to identify the role economic policy played during the crisis and the subsequent process of economic recovery. Our analysis indicates that only Mexico upheld and maintained its economic policy, including its fiscal policy, subject to the restrictions of the economic model that led to the crisis. Although Brazil did the same to confront the crisis, during its recovery process it broke with this restriction. Finally, Argentina, South Korea and Russia characterized themselves by breaking from the crisis, although in differing degrees, through the restriction of economic policy, a stance that has been kept to since then.

Keywords: financial crisis, economic policy, fiscal policy, economic recovery.

* Investigador del Instituto de Investigaciones Económicas de la UNAM. Correo electrónico: aleph3_98@yahoo.com

** Profesor de la Facultad de Estudios Superiores-Acatlán de la unAM. Correo electrónico: javierlapaguzman@hotmail.com

Los autores desean agradecer el apoyo financiero del proyecto UNAM-PAPIIT IN-306809 para la realización de esta investigación
\end{abstract}


Moritz Cruz y Javier Lapa

\section{CRISE ET RELANCE ÉCONOMIQUE: LE RÔLE DE LA POLITIQUE FISCALE Résumé}

Nous développons une analyse comparative de cinq économies qui ont connu des crises financières récemment (le Mexique 1994, la Corée du Sud 1997, la Russie 1998, le Brésil 1998 et l'Argentine 2001), dans le but d'identifier le rôle que la politique économique a joué pendant la crise et le processus postérieur de relance de l'économie. Notre analyse montre que seul le Mexique a continué à soumettre sa politique économique, y compris sur le plan fiscal, aux restrictions déterminées par le modèle économique qui fut à l'origine de la crise. Le Brésil, lui, bien qu'ayant d'abord fait la même chose pour faire face à la crise, a ensuite mis fin à cette limitation pendant son processus de relance. Finalement, l'Argentine, la Corée et la Russie se sont démarquées en mettant fin depuis la crise même, bien qu’à des degrés divers, à la restriction de leur politique économique, posture qu'elles ont maintenue depuis lors.

Mots clefs : crise financière, politique économique, politique fiscale, récupération économique.

\section{CRISE E RECUPERAÇÃO ECONÔMICA: O PAPEL DA POLÍTICA FISCAL Resumo}

Desenvolvemos uma análise comparativa de cinco economias que experimentaram crises financeiras recentemente (México 1994, Coréia do Sul 1997, Rússia 1998, Brasil 1998 e Argentina 2001), com o propósito de identificar o papel que a política fiscal jogou durante a crise o posterior processo de recuperação econômica. Nossa análise indica que unicamente México enfrentou e manteve sua política econômica, incluindo a fiscal, sujeita às restriçốes do modelo econômico que originou a crise. Ainda que Brasil tivesse feito o mesmo para enfrentar a crise, durante o processo de recuperaçáo rompeu com dita restrição. Finalmente, Argentina, Coréia e Rússia se caracterizaram por romper desde a mesma crise, ainda que com diferentes graduaçôes, com a restrição de política econômica, postura que se mantém desde então.

Palavras-chave: crise financeira, política econômica, política fiscal, recuperação econômica.

危机与经济复苏: 财政政策的角色

摘要：

为研究危机期间经济政策的作用及经济复苏过程, 本文比较分析了最近经 历金融危机的五个经济体（1994年的墨西哥、1997年的韩国、1998年的 俄罗斯、1998年的巴西和2001年的阿根廷）。本文研究表明，只有墨西 哥采取并保持实施了包括财政政策在内的应对危机的经济措施，以监管、 控制经济模式中导致危机的因素。尽管巴西也采取了相同的应对危机的政 策, 但在经济复苏过程中却未能保持政策的连续性。本文最后指出, 虽然 阿根廷、韩国和俄罗斯应对危机的政策在某种程度上存在差异, 但其经济 管制政策自此却延续了下来。

关键词: 金融危机, 经济政策, 财政政策, 经济复苏. 


\section{INTRODUCCIÓN}

Desde mediados de la década de 1990 y hasta inicios de la del 2000 el mundo en desarrollo registró una oleada, en realidad un nuevo boom, de crisis económicas. ${ }^{1}$ La literatura al respecto se preocupó principalmente por indagar las causas de las mismas. La visión teórica heterodoxa, en particular la post-keynesiana, asoció como causa principal de las crisis el rápido proceso de apertura financiera (ver, inter alia, Arestis y Glickman, 2002, De Paula y Alves, 2000, y Cruz et al, 2006). ${ }^{2}$

Del nuevo boom de crisis, no obstante, una de las cuestiones que la literatura heterodoxa (y también la ortodoxa) prácticamente ignoró en plantear y, consecuentemente en responder (y que cobra vigencia en el ámbito de la reciente crisis global de 2008 respecto al debate de cómo superarla), fue el papel que la política fiscal jugó frente a la crisis y durante el posterior proceso de recuperación económica. ${ }^{3}$ Es decir, nunca se planteó la necesidad de conocer cómo las economías enfrentaron y superaron sus crisis, particularmente en un contexto donde la estrategia que las originó, es decir la rápida apertura financiera, impuso restricciones a su autonomía de política económica en sentido ex-ante y expost (ver Grabel, 1996). ${ }^{4}$

El objetivo de este trabajo es intentar llenar dicho vacío en la literatura al analizar el tipo de políticas que pusieron en juego Argentina, Corea, Brasil, México y Rusia durante sus respectivas crisis y durante sus procesos de recuperación económica. En este análisis, destacamos el papel de la política fiscal por dos razones. La primera se debe a que una política fiscal expansiva es sujeta,

1 Entre las más destacadas estuvieron la mexicana de 1994-95, la surasiática de 1997-98, la rusa de 1998, la brasileña de 1998-99 y la argentina de 2001. A estas crisis pueden agregarse, entre otras, la ecuatoriana en 1999, la turca en 2001 y la dominicana en 2003.

2 La corriente ortodoxa, por su parte, señaló que las crisis observadas se trataban de una nueva generación de crisis, caracterizadas por ausencia de desequilibrios fiscales pero con la presencia de ataques especulativos (ver, por ejemplo, Obsfeld, 1996, y Calvo y Mendoza, 1996).

3 Existe ya una abundante literatura sobre el papel de la política fiscal para superar la crisis global de 2008. Algunos trabajos al respecto son Auerbach et al, 2010, Bénetrix y Lane, 2010, Farmer y Plotnikov, 2010, Leeper, 2010 y Pérez y Vernengo, 2010.

4 Aunque nos limitamos a resaltar el papel de la política fiscal, a lo largo del trabajo reconocemos y señalamos que un gobierno dispone de un conjunto más amplio de políticas a su disposición (la política monetaria, cambiaria, comercial, etcétera) para enfrentar y superar una crisis. 
tanto teórica como empíricamente, a intensos debates sobre sus beneficios o desventajas durante cualquier fase del ciclo económico. La posición convencional argumenta que no aporta ningún beneficio en términos de producto y empleo, sea que la economía esté en expansión o en recesión. Para la perspectiva keynesiana, la administración de la demanda vía la política fiscal es fundamental para la estabilidad del ciclo económico. En este sentido, ante una recesión o crisis, una política fiscal expansiva resulta fundamental para la recuperación económica. Con el análisis presentado en este trabajo, esperamos contribuir al debate que gira sobre el papel de la política fiscal expansiva, el cual ha resurgido, insistimos, a partir de la crisis económica global de 2008.

La segunda razón por la cual nos enfocamos en la política fiscal se debe a que si, como lo sugiere la perspectiva heterodoxa, el boom de crisis en las economías en desarrollo estuvo asociado a la adopción de una política de rápida apertura financiera, entonces los gobiernos de las economías en cuestión vieron restringida su política económica, incluida desde luego la política fiscal, en un sentido ex-ante y ex-post. Al analizar la respuesta de política económica a raíz de las crisis de las economías bajo estudio, podremos conocer si se mantuvo o no dicha restricción, y en este sentido explicar su evolución económica después de la crisis, es decir durante el proceso de recuperación.

Este trabajo tiene la siguiente estructura. La sección 2 describe cómo se restringe en sentido ex-ante y ex-post la política económica como consecuencia de la implementación de la estrategia de rápida apertura financiera. En esta misma sección, destacamos los argumentos teóricos de la postura teórica keynesiana que justifican la relevancia de una política fiscal expansionista en el crecimiento económico, particularmente en una situación de crisis o de recesión. La sección 3 describe la política económica de cada una de las economías analizadas frente a y después de sus crisis, haciendo énfasis en la política fiscal. La última sección presenta las conclusiones del trabajo.

\section{APERTURA FINANCIERA, RESTRICCIONES A LA POLÍTICA ECONÓMICA Y LA POLÍTICA FISCAL Y EL CRECIMIENTO ECONÓMICO: ALGUNAS CONSIDERACIONES TEÓRICAS}

Argentina, Brasil, Corea, México y Rusia no sólo comparten el hecho de haber experimentado una crisis financiera recientemente, sino también haber implementado, previo a sus respectivas crisis, reformas económicas similares. En efecto, todas estas naciones adoptaron la estrategia neoliberal (sintetizada en el llamado Consenso de Washington) como mecanismo de crecimiento económico, 
caracterizada, entre otros elementos, por una rápida y profunda liberalización comercial y financiera, priorización de la estabilidad macroeconómica tanto doméstica como externa y del tipo de cambio, así como por un acelerado proceso privatizador. Uno de los objetivos principales de esta estrategia fue crear un ambiente atractivo, de confianza y recompensa, para los inversionistas extranjeros, y así obtener grandes flujos de capital. En otras palabras, la estrategia de crecimiento económico adoptada se enfocó en mantener estable el sentimiento de los inversionistas (o del mercado) para garantizar que las entradas de capital fueran crecientes y estables. Esto dio como resultado que la estabilidad económica dependiera esencialmente de los flujos externos de capital, particularmente capital especulativo.

Mantener estable el sentimiento del mercado como objetivo de política significó, por un lado, un elevado costo al restringir en sentido ex-ante la autonomía de política económica, al enfocarla a la estabilidad macroeconómica y a la apertura financiera (y comercial). Y es que dicha restricción impide la adopción de medidas alternativas, entre ellas políticas de crecimiento liderado por la demanda agregada, donde el componente fiscal expansionista es fundamental, para promover metas de desarrollo y crecimiento económico. Por otra parte, la apertura neoliberal también significó restringir la política económica en sentido ex-post, debido a que ante un episodio de crisis, los gobiernos se ven obligados a reforzar las medidas inicialmente tomadas para recuperar la confianza de los inversionistas (Grabel, 1996).

La lógica de la restricción a la política económica ex-ante y ex-post debida a la adopción de una estrategia de rápida apertura financiera es, más explícitamente, la siguiente. El gobierno de un país (especialmente uno en desarrollo) que busca atraer y mantener flujos de inversión externos (directos y de cartera) como estrategia para fomentar el crecimiento puede estar en términos de política económica seriamente restringido en un sentido ex-ante. Para dicho gobierno, crear un ambiente adecuado para atraer capital implicará adoptar un conjunto de políticas destinadas a asegurar la confianza y la recompensa de los inversionistas. Esta estrategia, insistimos, incluye políticas monetarias y fiscales restrictivas (en este sentido, evidentemente, se priorizan finanzas públicas sanas, ya sea balance presupuestario o superávit, a través de recortes en el gasto público y/o la creación de nuevos impuestos al consumo, principalmente) enfocadas exclusivamente en la estabilización de precios, manteniendo la tasa de interés y el tipo de cambio fuera de los niveles en los cuales serían más convenientes para el crecimiento económico (por ejemplo, una tasa de interés elevada y un tipo de cambio constantemente apreciado).

Por otro lado, en caso de una salida de capital o una crisis financiera las autoridades podrían verse obligadas a adoptar ciertas medidas para recuperar la 
confianza de los inversionistas y así revertir las salidas de capital y la crisis. Estas medidas, cuando el gobierno no desea reintroducir control de capitales y/o restricciones en la convertibilidad de la moneda u otro tipo de medidas regulatorias a la entrada y/o salida del capital externo, se traducen en una intensificación de las políticas inicialmente adoptadas. Por lo tanto, la autonomía política estará en un estado de restricción ex-post, situación que puede ser agravada cuando el país en crisis recibe apoyo financiero de alguna institución multilateral o de otros gobiernos. Por lo general dichos apoyos van acompańados de condiciones en términos de política económica.

La restricción a la política económica, incluida la fiscal, tiene importantes repercusiones en el crecimiento económico desde la perspectiva teórica keynesiana, es decir desde la perspectiva de los modelos de crecimiento liderados por la demanda. Esto es así porque desde dicha perspectiva el componente de la demanda fundamental para estabilizar el ciclo económico es el gasto público. Esta característica se agudiza durante periodos de recesión o crisis económica ya que ningún otro componente de la demanda agregada es capaz de recuperarse de manera autónoma. ${ }^{5}$ Asimismo, el papel del gasto público en el crecimiento económico no se limita a regular la demanda agregada sino a impactar positivamente en la oferta, al expandir la infraestructura nacional, apoyar proyectos de investigación y desarrollo y mejorar la calidad del capital humano al ofrecerle más y mejor educación y servicios de salud. Es decir, el gasto público, de acuerdo con la perspectiva keynesiana, tiene indiscutiblemente efectos positivos en el crecimiento económico tanto en el corto como en el largo plazos. Si por alguna razón la capacidad de un gobierno se ve restringida para hacer uso adecuado de la política fiscal (es decir, a discreción de acuerdo al ciclo económico), evidentemente el crecimiento económico se verá afectado en la misma dirección, y con mayores consecuencias negativas, insistimos, si la economía enfrenta una crisis o recesión.

Más precisamente, la perspectiva teórica keynesiana (que asume al dinero endógeno, la existencia de capacidades productivas ociosas y la determinación de los niveles de producto y empleo en función de la demanda efectiva) argumenta que los efectos que genera el déficit público en la demanda agregada son

5 La única excepción podrían ser las exportaciones, pero si acaso ocurre un crecimiento significativo de las mismas durante una crisis, al mismo no podría denominársele de otra forma sino como de una afortunada coincidencia. 
diametralmente distintos a los señalados por el enfoque teórico convencional (Wray, 2007). ${ }^{6}$

En efecto, al expandirse el gasto público, supongamos vía déficit fiscal, especialmente en un contexto de lento crecimiento o crisis económica, de inmediato el empleo y el consumo aumentan, rompiendo de esta manera las expectativas negativas de los empresarios sobre sus decisiones de no invertir y/o mantener ociosa su capacidad productiva (rompiendo como resultado el ciclo acumulativo negativo de crecimiento). ${ }^{7}$ Más precisamente, "cualquier incremento en los gastos del gobierno en bienes y servicios producidos por el sector privado, ceteris paribus, incrementará las ventas de las industrias, por lo cual, estimulará a los empresarios a aumentar el empleo especialmente en las industrias donde el gobierno hace las compras directamente..." (Davidson, 2007: 65). Esto equivale a garantizar que un gasto público expansivo aliente en sentido optimista los "espíritus animales" de los empresarios. Una vez que las expectativas de los empresarios empiezan a cambiar en sentido optimista, ellos harán uso de la capacidad ociosa instalada, demandado mayor mano de obra, y eventualmente realizando

6 Desde la perspectiva de la teoría neoclásica, es decir, de la visión convencional, se niega la efectividad de la política fiscal para incidir en el crecimiento económico. Dicha tesis, que parte del supuesto del cumplimento de la ley de Say, lo cual conlleva, entre otros resultados, el supuesto de plena ocupación de los factores productivos, afirma que cuando se implementa una política fiscal expansiva el nivel de actividad económica no se verá afectado, al menos no en el largo plazo. En el mejor de los casos, su efecto expansivo se reducirá al corto plazo y será momentáneo, ya que al retornar el punto inicial se habrán generado graves problemas como un mayor nivel de inflación y una tasa de interés más elevada, con el consecuente incremento en la deuda de los agentes económicos, incluido la del gobierno, la apreciación del tipo de cambio y, por lo tanto, el deterioro de la balanza comercial. Bajo este marco teórico, la solución al insuficiente crecimiento económico (e implícitamente a alguna crisis económica) radica exclusivamente en flexibilizar el mercado laboral, ya que es en éste donde se determina el nivel de actividad económica. Así, en la medida en que el gobierno instrumente medidas enfocadas a flexibilizar el mercado laboral, como cambios en las políticas de beneficio al desempleo, de salarios mínimos, de la legislación de los sindicatos, etcétera (ver Carlin y Soskice, 2006), es decir medidas enfocadas a eficientar el lado de la oferta de la economía, se garantizará mayor crecimiento económico (o el pronto regreso al equilibrio de pleno empleo).

7 De hecho, independientemente de la fase del ciclo económico en que se encuentre la economía, el objetivo primario del gasto de gobierno debe ser mantener balanceada la tasa total de gasto en bienes y servicios en la economía, incrementándolo si el gasto privado es menor al nivel de pleno empleo y reduciéndolo si la demanda agregada excede el nivel de pleno empleo (Davidson, 2007: 66). 
mayores inversiones, expandiendo así su capacidad productiva. Esta dinámica positiva incrementará, en suma, la demanda efectiva, con lo que el empleo, el consumo y el ingreso harán lo mismo, iniciándose así un círculo virtuoso acumulativo de crecimiento.

Es importante destacar, por otra parte, que en las economías en desarrollo, por lo regular, existe un claro desequilibrio entre la capacidad productiva y la mano de obra, siendo ésta superior a aquélla, lo que genera un grave problema de desempleo. Con poca mano de obra empleada, el consumo resulta insuficiente para estimular a los empresarios a expandir la capacidad instalada, perpetuándose así un ciclo de insuficiente demanda agregada-alto desempleo-bajo crecimiento. Por esta razón, la inversión pública resulta fundamental para iniciar y sostener un ciclo de crecimiento económico tanto en el corto como en el largo plazos ya que su efecto resulta ser indiscutiblemente positivo: no sólo expande la demanda efectiva y dinamiza el crecimiento (y disminuye el desempleo) hoy, sino también disminuye el desempleo de mañana al incrementar la capacidad instalada.

Al mismo tiempo, los beneficios del gasto público no se limitan, es importante destacarlo, a una mera expansión de la demanda agregada. El gasto público productivo (léase en infraestructura, maquinaria y equipo y apoyo a la ciencia y a la tecnología) contribuye también a expandir y mejorar el lado de la oferta de la economía. En este sentido, la expansión sostenida del gasto público sienta las bases para el crecimiento económico en el largo plazo.

Como consecuencia, para lograr el objetivo de crecimiento, la teoría keynesiana sugiere la reactivación y control permanente de la demanda agregada mediante la inserción del gobierno en la conducción económica a través del uso de sus instrumentos de política económica, especialmente la política fiscal (expansiva). Así, el mantenimiento de un ingente gasto público (no necesariamente reflejado en un déficit fiscal) debería ser el estado normal de cualquier economía capitalista. Por ende, para esta visión teórica, la cuestión a resolver no está en si debe o no haber gasto público expansivo, sino el nivel y el financiamiento del mismo. Evidentemente, el gasto público, no así el ingreso público, debe ampliarse cuando la economía se encuentre en recesión o bien enfrente una crisis.

En suma, desde la perspectiva keynesiana, la política fiscal no puede ni debe permanecer estática a lo largo del ciclo económico, y menos durante una recesión o crisis económica. Cuando se imponen restricciones a la misma en afán de buscar otros mecanismos automáticos de crecimiento económico, las consecuencias negativas en éste en el corto y el largo plazos serán sin duda considerables. 


\section{CRISIS, RECUPERACIÓN ECONÓMICA Y LA POLÍTICA FISCAL: EVIDENCIA EMPÍRICA DE ARGENTINA, BRASIL, COREA, MÉXICO Y RUSIA}

De los desplomes económicos de Argentina, Brasil, Corea, México y Rusia a raíz de sus respectivas crisis, resaltan los casos de Argentina y Brasil, con el primero registrando la caída más profunda, $-10.9 \%$ en 2002, mientras el segundo siendo el menos afectado ya que su PIB en 1998, año de la crisis, quedó en $0 \%$. A Argentina le siguen Corea, México y Rusia, con contracciones de $-6.8 \%$ en 1998, $-6.1 \%$ en 1995 y $-5.3 \%$ en 1998 , respectivamente. La interrogante que surge de inmediato al señalar estos desplomes económicos es cómo respondió cada economía, en término de política económica, a tales situaciones. En particular, resulta interesante saber si la demanda efectiva, y con ella el crecimiento económico, fue estimulada a través de una política fiscal expansiva.

La evolución durante la recuperación económica de cada país destacado es diferente, pues Argentina registró la tasa de crecimiento económico más alta durante el periodo post-crisis, con una tasa promedio de $8.5 \%$. A ella le siguen Rusia, $6.9 \%$ y Corea, 5.3\%, mientras Brasil y México registran prácticamente la misma tasa, 3.7\% (ver Cuadro 1). La interrogante que surge al observar estas disparidades en la evolución económica post-crisis en estas economías es cómo evolucionó la política económica, especialmente la fiscal, a lo largo del periodo post-crisis en cada economía.

Para responder a ambas cuestiones, y conocer entonces si las restricciones de política económica se mantuvieron o no, analizamos y comparamos a lo largo de la presente sección los programas de política económica de cada país, enfatizando la evolución que la política fiscal tuvo en cada uno de ellos.

Los programas de política económica llevados a cabo por los cinco países bajo análisis, en términos de la respuesta inmediata a la crisis económica, pueden ser

Cuadro 1. Tasas de crecimiento del PIB post-crisis de Argentina, Brasil, Corea del Sur, México y Rusia

\begin{tabular}{lllllllllllllll}
\hline \multicolumn{1}{c}{ Pais } & 1996 & 1997 & 1998 & 1999 & 2000 & 2001 & 2002 & 2003 & 2004 & 2005 & 2006 & 2007 & 2008 & Promedio \\
\hline Argentina & & & & & & & & 8.8 & 9.0 & 9.2 & 8.5 & 8.7 & 7.0 & 8.5 \\
Brasil & & & & 0.3 & 4.3 & 1.3 & 2.7 & 1.2 & 5.7 & 3.2 & 4.0 & 5.7 & 5.1 & 3.7 \\
Corea & & & & 9.5 & 8.5 & 4.0 & 7.2 & 2.8 & 4.6 & 4.0 & 5.2 & 5.1 & 2.2 & 5.3 \\
México & 5.2 & 6.8 & 4.9 & 3.9 & 6.6 & -0.2 & 0.8 & 1.7 & 4.0 & 3.2 & 5.1 & 3.3 & 1.4 & 3.6 \\
Rusia & & & & 6.4 & 10.0 & 5.1 & 4.7 & 7.3 & 7.2 & 6.4 & 7.7 & 8.1 & 5.6 & 6.9 \\
\hline
\end{tabular}

Fuente: Elaboración propia con base en INEGI, IBGE, INDEC y los bancos nacionales de Corea y Rusia. 
clasificados de la siguiente manera: en un primer grupo, los de México y Brasil, cuya principal característica fue la profundización de la estrategia neoliberal como mecanismo de respuesta a la crisis, acentuando así su restricción de política económica; y en un segundo grupo los de Argentina, Corea y Rusia, que se caracterizaron por una serie de medidas contrarias al pensamiento convencional, rompiendo en este sentido su restricción de política económica, incluida desde luego la fiscal.

Para Brasil y México, el principal objetivo en términos de política económica ante su respectiva crisis consistió en recuperar la confianza de los inversionistas extranjeros, para lo cual fue necesario recurrir al endeudamiento externo. Los cuantiosos préstamos que recibieron estos países de los distintos organismos internacionales, ${ }^{8}$ fueron concedidos bajo una serie de condicionantes, entre las que destacaron: mejorar el balance fiscal, la reconstrucción de las reservas internacionales y una disminución sustancial del nivel de inflación (a un máximo de $5 \%$ anual). Además, a ambos países se les recomendó mantener tasas de interés relativamente elevadas, especialmente en comparación con las de otros mercados emergentes, y pagar puntualmente su deuda de corto plazo (a lo que se destinó la mayor parte de los préstamos recibidos). Lo anterior reflejó los caracteres contractivos de las políticas monetarias y fiscal implementados inmediatamente frente a sus crisis. En este contexto, México, por ejemplo, registró en 1995 un magro déficit fiscal, de apenas $0.3 \%$ del PIB. Así, aunque en este año el gasto público creció marginalmente, los ingresos públicos crecieron mucho más (ver Cuadro 2). Brasil, por su parte, registró en 1999 un superávit fiscal importante de $1.8 \%$ del PIB, como consecuencia de la medida conjunta de reducir el gasto y aumentar los ingresos públicos (ver Cuadro 3). En este sentido, y como puede observarse, la política fiscal de Brasil resultó bastante más radical que la efectuada en la economía mexicana.

Es importante destacar que a pesar de que en ambas economías las distintas medidas implementadas para recuperar la confianza de los inversionistas fueron respaldadas por los cuantiosos préstamos otorgados por los organismos internacionales, la afluencia de capitales extranjeros nunca alcanzó los niveles previos a las crisis. Asimismo, los préstamos que recibieron, contribuyeron exclusivamente a estabilizar el tipo de cambio (tras la fuerte devaluación que sus monedas experimentaron) y a reducir el nivel de inflación, pero restringieron aún más

8 México, por ejemplo, recibió cerca de $\$ 50$ billones de dólares de parte de instituciones multilaterales (particularmente del FMI) y de gobiernos foráneos (principalmente del gobierno estadounidense). Esta situación se repitió en Brasil, donde el monto del endeudamiento ascendió a $\$ 41$ billones de dólares. 
su autonomía de política económica debido a que la estabilidad económica se mantuvo dependiente de los flujos de capital extranjero.

En suma, para los casos de Brasil y México, la respuesta de política para enfrentar la crisis se caracterizó por una profundización de las políticas fiscal y monetaria restrictivas, así como por un reforzamiento de la apertura comercial, de liberalización financiera y de disminución de la participación del Estado en la vida económica del país. Estas medidas restringieron en un sentido ex-post la autonomía de su política económica. En particular, sin política fiscal expansiva, la demanda agregada no se reactivó, al menos no de manera inducida directamente por el gobierno. A esto puede atribuirse el que en ambos países el programa de recuperación económica haya sido incapaz de reinstaurar rápidamente los niveles de actividad económica pre-crisis.

Revisemos ahora la política económica instrumentada inmediatamente frente a la crisis por las economías que rompieron con la restricción impuesta por la estrategia neoliberal. El primer paso hacia el rompimiento de la restricción de política ex-post consistió en no priorizar el cumplimento de las obligaciones de deuda, es decir en no satisfacer a los inversionistas o el sentimiento del mercado. Así, Argentina declaró la moratoria permanente de deuda más grande de la historia del capitalismo; Rusia, por su parte, negoció el monto de su deuda externa (sustituyendo su debilidad como deudor con organización y poder político); ${ }^{9}$ Corea, finalmente, logró reestructurar el monto de la suya. Estas decisiones, complementadas por aquéllas en materia fiscal y monetaria contrarias a la estrategia neoliberal, como veremos enseguida, caracterizaron a los programas de recuperación económica de estos tres países. En suma, se priorizó la recuperación de la actividad económica real (por ejemplo, el piB y el empleo) sobre la financiera.

Para lograr la recuperación económica real, Argentina, Corea y Rusia se dieron a la tarea de mejorar el funcionamiento institucional de sus economías y restablecer el sistema interno de pagos, este último a través del banco central. Por ejemplo, en el caso de Corea y Rusia, se inyectó liquidez monetaria para superar el colapso del sistema de pagos, cuidando no rebasar los límites que abocarían a una mayor inflación y por ende, a una mayor devaluación. Argentina prefirió utilizar al banco central para estabilizar su moneda, por lo que fijó un tipo de cambio estable, pero competitivo, que aunado a las intervenciones en el mercado de cambios (a través

9 Por ejemplo, en el caso de los títulos públicos de corto plazo, logró una ampliación de varios años de su fecha de vencimiento, y una disminución del valor real de éstos, que pasó del $12 \%$ al $1 \%$ del рів. De igual forma logró una importante restructuración en el monto a pagar por concepto de deuda externa (Banco Nacional de Rusia, 2010). 
de la venta de dólares y la restricción del flujo de pesos fuera del sistema bancario) benefició a sus exportaciones. Estos ejemplos ilustran el caso omiso a la recomendación de mantener un control riguroso de la oferta monetaria y la renuencia a mecanismos severos de anclaje de la paridad nominal.

Adicionalmente, estas economías decidieron elevar sus tasas de interés en el corto plazo para frenar el deterioro del tipo de cambio, pero una vez que éste se estabilizó, las redujeron paulatinamente. ${ }^{10}$ También se implementó una serie de medidas encaminadas a limitar la entrada de inversión extranjera de corto plazo y a dirigir los capitales a inversiones de largo plazo, contribuyendo ambas medidas al control de la especulación (ver Grabel, 2003). ${ }^{11}$ Dichas medidas sirvieron además para fortalecer el sistema financiero de estos países ante los efectos adversos del contagio financiero, lo que se tradujo en la estabilidad de divisas, que aunada a mejores mecanismos de inversión logró atraer importantes flujos de capital extranjero. De igual forma, en el ámbito comercial, estos países decidieron incrementar el control gubernamental; el gobierno coreano, por ejemplo, incrementó su recaudación por concepto de aranceles (en 2000 llegó a representar el $6.5 \%$ de los impuestos totales) e implementó diversos programas de apoyo a la pequeña y mediana empresa exportadora (ver más adelante).

En materia fiscal, al haber priorizado el sector real sobre el financiero, a través de la moratoria y/o renegociaciones de deuda, estas economías lograron la autonomía necesaria para implementar programas de gasto público expansionistas. Corea, por ejemplo, registró en 1998 un amplio déficit fiscal, de 3.8\% del piв (ver Cuadro 4). Rusia alcanzó uno de $4.2 \%$ del PIB en ese mismo año (ver Cuadro 5) y Argentina alcanzó uno de casi 4\% del PIB en 2001 y de 0.5\% del PIB en 2002 (ver Cuadro 6).

En suma, Argentina, Corea y Rusia rompieron con los paradigmas del modelo neoliberal logrando así independencia en términos de su política económica. Con ésta en sus manos, implementaron medidas alternativas encaminadas a

10 Dicho aumento fue moderado y de corta duración; por ejemplo, las tasas de interés en Corea subieron a $35 \%$, y se mantuvieron en esos niveles máximos sólo algunos días, después bajaron rápidamente a niveles inferiores a los que prevalecían antes de la crisis (llegando a $5 \%$ en diciembre de 1999). En Rusia la tasa de interés del principal instrumento de deuda (GKo) pasó de $84.2 \%$ en 1998, a 16\% en 1999 y a $12.8 \%$ en el año siguiente (Banco Nacional de Corea y Banco Nacional de Rusia, 2010).

11 Con el ánimo de estabilizar la paridad cambiaria, el gobierno argentino también ordenó que todo ingreso en dólares por concepto de exportaciones superior al millón de dólares, fuera entregado al banco central a cambio de pesos; de esta manera incrementó la oferta de dólares disponibles. 
promover la recuperación y el crecimiento económico. En este contexto, como resaltamos, destaca el papel que tuvo la política fiscal.

Ahora bien, respecto a los procesos de recuperación económica, la evidencia indica, como veremos, que todas las economías bajo estudio, excepto la mexicana, mantuvieron una política económica distinta a la sugerida por la estrategia neoliberal, incluida desde luego la política fiscal. Como consecuencia, el desempeño económico de las economías que rompieron su restricción de política económica después de sus respectivas crisis ha sido elevado y sostenido (aunque para Brasil en realidad puede hablarse de crecimiento rápido y sostenido a partir de 2004), a diferencia del registrado por la economía mexicana.

Como se aprecia en el Cuadro 2, en México, pese a la contracción económica consecuencia de la crisis, la política fiscal restrictiva en 1996 permanece apenas inalterada, reflejándose en el mantenimiento del equilibrio fiscal. De hecho, en ese año, los ingresos fiscales como porcentaje del PIB, con respecto al año anterior, aumentan marginalmente y aunque el gasto crece, también lo hace insignificantemente. Más aún, en los años subsiguientes a 1996, cuando la urgencia por recuperar el PIB (y el empleo) perdido por la crisis se acentúa, la tendencia del gasto y del ingreso público se mantiene sin cambio, reflejándose en mínimos déficits fiscales. De hecho, el gasto público no alcanza nunca niveles pre-crisis, lo cual indica la priorización del gobierno en aspectos de estabilidad macroeconómica sobre la economía real. No es casual, así, que la economía mexicana haya crecido de manera insuficiente inmediatamente después de la crisis y en los años que le siguieron. Es importante destacar que el registro positivo de crecimiento durante el año inmediato a la crisis se debió principalmente al favorable entorno externo, con la economía estadounidense creciendo sostenidamente y arrastrando a la economía mexicana vía exportaciones (éstas crecieron $18.2 \%$ en 1996). ${ }^{12}$

12 Para ilustrar la magnitud de la abulia fiscal de las autoridades mexicanas, realicemos un simple ejercicio que responda a la pregunta de cuánto debió haber crecido el gasto público en 1996, permaneciendo todo lo demás constante, para recuperar el nivel de producto de 1994. La respuesta es sencilla si conocemos el multiplicador de la demanda keynesiano de 1996, el cual fue de 1.8 (el multiplicador se calcula como $1 / \mathrm{m}+\mathrm{s}$, donde $\mathrm{m}$ y s, expresadas como porcentaje del PIB, son importaciones y ahorro total, respectivamente). Si el PIB, en términos reales, fue de $\$ 1312$ billones de pesos en 1994, entonces el gasto de gobierno en 1996 debió incrementarse la monumental suma de $\$ 590$ billones de pesos para alcanzar el nivel previo a la crisis. Aunque en términos prácticos ejercer esta cantidad puede resultar, por diversas razones, inalcanzable, sí ilustra, de cualquier forma, que un déficit fiscal de $0.01 \%$ del PIB o un aumento de $1 \%$ del gasto público en 1996, es decir lo hecho en materia fiscal ante la crisis y posteriormente, fue claramente insuficiente para impulsar y mantener una verdadera recuperación económica. 
Moritz Cruz y Javier Lapa

Cuadro 2. Balance fiscal de México

(\% del PIB)

\begin{tabular}{cccc}
\hline Año & Ingresos & Gastos & Balance \\
\hline 1990 & 14.12 & 17.43 & -3.31 \\
1991 & 15.05 & 16.36 & -1.32 \\
1992 & 17.01 & 16.29 & 0.72 \\
1993 & 14.35 & 13.84 & 0.50 \\
1994 & 14.15 & 14.27 & -0.12 \\
1995 & 14.31 & 14.34 & -0.03 \\
1996 & 14.50 & 14.49 & 0.01 \\
1997 & 14.47 & 15.31 & -0.84 \\
1998 & 13.73 & 14.82 & -1.10 \\
1999 & 13.79 & 14.98 & -1.19 \\
2000 & 14.52 & 15.71 & -1.19 \\
2001 & 14.74 & 15.65 & -0.91 \\
2002 & 14.91 & 15.78 & -0.87 \\
2003 & 14.99 & 15.84 & -0.84 \\
2004 & 15.74 & 16.05 & -0.31 \\
2005 & 15.85 & 16.15 & -0.29 \\
2006 & 15.82 & 16.02 & -0.19 \\
2007 & 15.32 & 17.28 & -1.96 \\
\hline
\end{tabular}

Fuente: CEPAL-ILPS. Estadísticas de las Finanzas Públicas en América Latina (2010).

Brasil, por su parte, como hemos señalado, presenta importantes similitudes con respecto a México en materia fiscal, aunque sólo durante la respuesta a su crisis. Recordemos que ante la crisis, el gobierno brasileño decidió implementar un paquete fiscal basado en las recomendaciones del Fondo Monetario Internacional (FMI), por lo que en 1999 incrementó los ingresos públicos a la par de reducir el gasto con respecto al año anterior. Esto dio como resultado un importante superávit fiscal, de casi $2 \%$ del рів (ver Cuadro 3). Esta tendencia se acentuó el año siguiente, cuando el superávit público se incrementó a 3.2\% del PIB. Así, en el caso de Brasil, es posible argumentar que como respuesta a la crisis, la política fiscal se mantuvo restringida en sentido ex-post, de tal suerte que la misma no contribuyó a la recuperación económica. Ésta se dio, como en el caso de la economía mexicana, vía el sector externo al incrementarse las 
exportaciones como consecuencia de la importante devaluación de la moneda ocurrida durante la crisis. En efecto, la moneda brasileña, el real, se devaluó 64\% entre 1998 y 1999, al pasar de $\$ 1.1$ reales por dólar en 1998 a $\$ 1.8$ reales por dólar en 1999. Con esta devaluación, las exportaciones crecieron $5.7 \%$ en 1999 y $12.9 \%$ en 2000 .

No obstante, el comportamiento del balance fiscal a partir del año 2000, en el que desde entonces se registran déficits, en algunos casos significativo, como en 2005, de 3.5\% del PIB, sugiere que el gobierno brasileńo se percató de la necesidad de contribuir al crecimiento estimulando la demanda, y haciendo crecer al mismo tiempo la oferta, mediante el gasto público. En este sentido, el gasto público como porcentaje del PIB a partir de 2001 supera el nivel pre-crisis, y alcanza a partir de 2005 una participación de $26 \%$ en el PIB. El aumento paulatino del gasto público, con su impacto en la demanda efectiva y en la oferta, fue sentando las bases, como ha ocurrido, para el crecimiento rápido y sostenido en el largo plazo.

Cuadro 3. Balance fiscal de Brasil

(\% del PIB)

\begin{tabular}{cccc}
\hline Año & Ingresos & Gastos & Balance \\
\hline 1994 & 21.56 & 20.20 & 1.52 \\
1995 & 21.67 & 20.47 & 1.28 \\
1996 & 21.75 & 20.51 & 1.18 \\
1997 & 21.21 & 20.82 & 0.39 \\
1998 & 21.05 & 21.51 & -0.45 \\
1999 & 22.15 & 20.07 & 1.86 \\
2000 & 22.19 & 18.92 & 3.19 \\
2001 & 20.04 & 21.82 & -1.78 \\
2002 & 21.63 & 22.79 & -1.16 \\
2003 & 21.92 & 25.25 & -3.33 \\
2004 & 21.55 & 23.40 & -1.85 \\
2005 & 22.67 & 26.26 & -3.59 \\
2006 & 23.33 & 26.27 & -2.94 \\
2007 & 24.37 & 26.33 & -1.96 \\
\hline
\end{tabular}

Fuente: Elaboración propia con base en el Instituto Brasileño de Geografía y Estadística (IBGE, 2010). 
En el caso de Corea, la crisis económica la enfrentó, como hemos destacado, con un ingente gasto público, reflejándose en importantes déficits fiscales. Dicho gasto tocó aspectos tanto de la demanda como de oferta de la economía. Por ejemplo, la política fiscal se orientó a apoyar el desarrollo del sector industrial y tecnológico, el cual se fomentó a través de una serie de incentivos fiscales a las pequeñas y medianas empresas. ${ }^{13}$ Además, el gobierno llevó a cabo programas de obras públicas e incentivó la creación de nuevas empresas (mediante apoyos y subsidios privilegiados), con la intención de generar empleos y así, contrarrestar el aumento de la pobreza entre los sectores de menores ingresos. Otra de las medidas fiscales destinadas a estimular la demanda fue la implementación de una serie de apoyos a los ingresos de los más pobres, así como la implementación de programas de capacitación para el reempleo y para el mantenimiento del mismo. ${ }^{14}$ Esta serie de medidas fiscales explican el considerable aumento del gasto público en los ańos 1998 y 1999. En efecto, el gasto público pasó de 19.8\% del PIB en 1997 a 22\% del PIB en 1999. Este año, de hecho, registra un considerable déficit fiscal, de $2.3 \%$ del PIB, aunque relativamente menor al de 1998, cuando alcanzó 3.7\% del pIB (ver Cuadro 4).

Una conclusión falaz al observar los datos del Cuadro 4 sería que una vez superada la crisis, es decir a partir del año 2000, Corea cambió radicalmente su postura respecto a la relevancia del gasto público en la dinámica de la demanda y del crecimiento económico, ya que, como se observa, el balance fiscal está en equilibrio o es superavitario. No obstante, si se analiza con atención la evolución del gasto público a partir de dicho ańo, puede notarse que siempre se ubica, particularmente en 2006, muy por encima de los niveles pre-crisis. En este sentido, es posible argumentar que el gobierno coreano no desestimó la relevancia del gasto público en la dinámica económica, manteniendo así su autonomía de política económica recuperada durante la crisis. Al mismo tiempo, es importante recordar que el incremento de los ingresos públicos, ante la ausencia de nuevos impuestos, tiene mucho que ver con el mejor desempeńo de la economía.

El gobierno ruso, por su parte, enfrentó la crisis económica a través de una serie de incentivos fiscales otorgados al sector productivo. Como resultado, el gasto público en 1999 se mantuvo prácticamente constante con respecto al año

13 Por ejemplo, la devolución de impuestos, tarifas preferenciales de los servicios públicos y asesoría para un mejor funcionamiento.

14 Sólo para las políticas de apoyo a los ingresos y al empleo, se asignaron 10.1 trillones de won en 1998, 15.8 en 1999 y 6.7 en 2000; es decir, en promedio se gastó $1.2 \%$ del PIB. 
Cuadro 4. Balance fiscal de Corea

$(\%$ del PIB)

\begin{tabular}{cccc}
\hline Año & Ingresos & Gastos & Balance \\
\hline 1995 & 17.78 & 17.47 & 0.30 \\
1996 & 18.55 & 18.32 & 0.24 \\
1997 & 18.44 & 19.82 & -1.37 \\
1998 & 19.29 & 23.04 & -3.74 \\
1999 & 19.66 & 22.04 & -2.38 \\
2000 & 22.51 & 21.43 & 1.08 \\
2001 & 22.11 & 21.00 & 1.12 \\
2002 & 22.03 & 18.88 & 3.15 \\
2003 & 22.41 & 21.42 & 1.00 \\
2004 & 21.62 & 20.99 & 0.63 \\
2005 & 22.13 & 21.72 & 0.40 \\
2006 & 23.06 & 22.66 & 0.40 \\
2007 & 24.99 & 21.52 & 3.47 \\
2008 & 24.43 & 23.27 & 1.16 \\
\hline
\end{tabular}

Fuente: Elaboración propia con base en el Banco de Corea (2010).

anterior, mientras que el ingreso público pasó de $9.8 \%$ a $12.6 \%$ del PIB ${ }^{15}$ (ver Cuadro 5) debido al mejoramiento del sistema recaudatorio y al buen comportamiento que tuvieron los precios del petróleo durante ese año. Además, debido a la moratoria de la deuda externa y a la incapacidad de cubrir la interna, la cantidad destinada a su pago disminuyó de $5.3 \%$ a $2.7 \%$ del piB, con lo cual se facilitó la expansión del gasto público. Dicha expansión se vio potenciada por la ampliación de la regulación estatal, permitiendo, al mismo tiempo, reorganizar estratégicamente el gasto de gobierno y mejorar la distribución de los ingresos presupuestarios entre los distintos niveles de gobierno. En los años siguientes, el

15 Dichos ingresos le proporcionaron al gobierno ruso cierta capacidad de ahorro para afrontar el pago de intereses de la deuda externa, eludir la necesidad de buscar nuevos recursos para financiar el gasto público y, además, favoreció el proceso de institucionalización de la economía, que comenzó por normalizar las actividades del propio aparato estatal, dotándole de mejores instrumentos y de mayor autoridad política para regular las actividades económicas. 
ingreso público se incrementó notablemente como resultado del buen comportamiento de los precios internacionales de las materias primas; no obstante dicho ingreso registró una caída en 2000, vuelve a su nivel de 1999 en 2001. Así, la política fiscal rusa inmediata y posterior a la crisis denotó un carácter contracíclico, fundamental para la recuperación económica observada.

Cuadro 5. Balance fiscal de Rusia

(\% del PIB)

\begin{tabular}{cccc}
\hline Año & Ingresos & Gastos & Balance \\
\hline 1995 & 13.2 & 18.1 & -4.9 \\
1996 & 11.8 & 19.7 & -7.9 \\
1997 & 11.6 & 18.8 & -7.2 \\
1998 & 9.8 & 14 & -4.2 \\
1999 & 12.6 & 14.1 & -1.5 \\
2000 & 15.4 & 13 & 2.4 \\
2001 & 17.6 & 14.6 & 3 \\
\hline
\end{tabular}

Fuente: Elaboración propia con base en el Banco de Rusia (2010).

El caso de Argentina, finalmente, es similar al de Rusia en el sentido de que también declaró con el inicio de la crisis, como señalamos anteriormente, su incapacidad de continuar sirviendo su deuda pública interna y externa, con lo cual la mayor disposición de recursos hizo posible su canalización a actividades productivas estimuladoras de la demanda agregada, dinamizando así el crecimiento económico. En este sentido, en 2002 no obstante que el déficit fiscal se mantiene, el mismo es considerablemente menor que el del año previo, pero el gasto público se incrementa (ver Cuadro 6). Esta evidencia sugiere el logro de la autonomía de política fiscal en plena crisis. La tendencia del gasto público a partir de dicho año, con excepción de 2004, es creciente. Al igual que Corea, a pesar del incremento sostenido del gasto público, el balance fiscal a partir de 2004 es superavitario. En este sentido, Argentina mantiene su autonomía de política fiscal durante el proceso de recuperación económica.

El incremento del ingreso público que observa Argentina, como en el caso de Rusia, es importante destacarlo, obedeció principalmente a la restructuración de su sistema tributario, con lo que mejoró la eficiencia de sus mecanismos recaudatorios. Adicionalmente se implementaron nuevos impuestos, por ejemplo, a las exportaciones (lo que permitió captar parte de las ganancias inesperadas 
obtenidas por los exportadores como resultado de la devaluación) y a las transacciones financieras. Ambos impuestos en conjunto representaron el $2.7 \%$ del PIB, lo que explica casi en su totalidad el superávit primario fiscal en 2004. En suma, los superávits observados tienen mayor relación con una mejor recaudación, que con una reducción del gasto. A lo anterior se sumaron los ingresos provenientes del favorable comportamiento de los precios de las materias primas en los mercados internacionales.

Cuadro 6. Balance fiscal de Argentina

(\% del PIB)

\begin{tabular}{cccc}
\hline Año & Ingresos & Gastos & Balance \\
\hline 1999 & 14.06 & 17.14 & -3.08 \\
2000 & 15.20 & 17.32 & -2.13 \\
2001 & 14.29 & 18.28 & -3.99 \\
2002 & 14.17 & 14.76 & -0.59 \\
2003 & 16.03 & 16.18 & -0.15 \\
2004 & 16.33 & 14.36 & 1.97 \\
2005 & 16.71 & 16.33 & 0.38 \\
2006 & 17.20 & 16.18 & 1.02 \\
2007 & 18.41 & 17.76 & 0.65 \\
\hline
\end{tabular}

Fuente: CEPAL-LPPS. Estadísticas de las Finanzas Públicas en América Latina (2010).

El gobierno argentino también priorizó la resolución al problema de desempleo y de la creciente pobreza, por lo que el gasto social fue uno de los principales componentes del gasto total. ${ }^{16}$ Asimismo, implementó una serie de incentivos fiscales orientados a fomentar el desarrollo del sector productivo.

En suma, aquellas economías que en el ámbito fiscal -Brasil, Corea, Rusia y Argentina- priorizaron la reactivación real de sus economías utilizando al gasto público como detonante de la demanda agregada pero también de la oferta,

16 Por ejemplo, uno de los principales programas encaminados a mitigar dichos problemas, fue el de apoyo a los ingresos de los jefes de familia desempleados. Que llegó a beneficiar al 20\% del total de hogares, de los cuales el $97.6 \%$ se encontraba por debajo de la línea de pobreza. 
lograron, a la par de la autonomía de política, un crecimiento económico postcrisis rápido y sostenido. Esta evidencia soporta el argumento keynesiano de que la política fiscal expansiva, junto con otras medidas de política consistentes con dicha expansión, son indispensables frente a una crisis económica y cruciales para un posterior proceso de recuperación.

\section{CONCLUSIONES}

En este trabajo analizamos la respuesta en términos de política económica, enfatizando en la política fiscal, de cinco economías en desarrollo que sufrieron crisis económicas recientemente. El análisis indicó que México fue la única economía que como respuesta a la crisis, y posteriormente durante su proceso de recuperación económica, profundizó las medidas de política que inicialmente dieron origen a su crisis. Es decir, desde la crisis la respuesta en términos de política fue mantener estable el sentimiento del mercado. Con ello, su autonomía de política económica, en particular su política fiscal, se mantuvo restringida, con lo cual se ha visto impedida de implementar medidas alternativas para promover el crecimiento económico. Recordemos que, desde la perspectiva de los modelos de crecimiento liderados por la demanda agregada, el gasto público resulta fundamental para mantener y/o restaurar la demanda efectiva, y con ello los niveles de inversión y de empleo. En una situación de crisis o de recesión, el gasto público se vuelve crucial para tal efecto. Desde esta perspectiva, el pobre crecimiento del gasto público ha contribuido al insuficiente crecimiento de la economía mexicana (poco más de $2 \%$ promedio anual) desde su crisis de 1994-1995.

Por otra parte, aunque Brasil respondió como México a su crisis, pero cambió su postura poco después, con lo que ganó autonomía de política económica. En este sentido, la política fiscal, monetaria, cambiaria, entre otras, que Brasil ha venido aplicando, ha contribuido al crecimiento sostenido observado post-crisis. En este contexto, su política fiscal ha sido expansiva, entendida como un crecimiento (no proporcional, desde luego) tanto del gasto como del ingreso público.

Finalmente, Argentina, Corea y Rusia, desde el inicio de sus respectivas crisis, rompieron con las restricciones de política económica impuestas por la adopción de la estrategia neoliberal. Así, la respuesta de política económica de cada economía consistió en un conjunto de medidas que priorizaba la reactivación de la economía real sobre la restauración de la confianza del sentimiento de mercado. En este contexto, destacó la implementación de una política fiscal 
expansionista, la cual contribuyó a la restauración de la demanda efectiva y al crecimiento económico sostenido post-crisis.

La evidencia empírica aquí presentada soporta, en suma, la propuesta de que una política fiscal expansionista es importante en el crecimiento económico, particularmente durante y después de una crisis económica, especialmente cuando es acompañada de políticas complementarias adecuadas, tales como una política monetaria y crediticia expansiva.

\section{BIBLIOGRAFÍA}

Arestis, P. y M. Glickman, "Financial Crisis in Southeast Asia: Dispelling Illusion in the Minskyan Way", en Cambridge Journal of Economics, vol. 26, 2002, pp. 237-60.

Auerbach, A., W. Galen, y B. Harris, "Activist Fiscal Policy", en Journal of Economic Literature, vol. 24, núm. 4, 2010, pp. 141-164.

Bénétrix, A. y P. Lane, "International Differences in Fiscal Policy During the Global Crisis", en NBER Working Papers, núm. 16346, 2010, pp. 1-46.

Bracho, G. y J. López, "The Economic Collapse of Russia”, en Banca Nazionale del Lavoro Quarterly Review, num. 232, 2005, pp. 53-89.

Calvo, A. y E. Mendoza, "Mexico's Balance-of-Payments: a Chronicle of a Death Foretold", en Journal of International Economics, vol. 41, 1996, pp. 236-264.

Carlin, W. y D. Soskice, Macroeconomics. Imperfections, Institutions and Policies, Inglaterra, Oxford University Press, 2006.

Cruz, M., E. Amann, y B. Walters, "Expectations, the Business Cycle and the Mexican Peso Crisis", en Cambridge Journal of Economics, vol. 30, 2006, pp. 701-722.

Davidson, P., John Maynard Keynes, Gran Bretaña, Palgrave Macmillan. 2007.

De Paula, L. y A. Alves, "External Financial Fragility and the 1998-1999 Brazilian Currency Crisis", en Journal of Post Keynesian Economics, vol. 22, núm. 4, 2000, pp. 589-617.

Farmer, R. y Plotnikov, D., "Does Fiscal Policy Matter? Blinder and Solow Revisited”, en NBER Working Paper, núm. 16644, 2010, pp. 1-34.

Grabel, I., "Marketing the Third World: the Contradictions of Portfolio Investment in the Global Economy", en World Development, vol. 24, núm. 11, 1996, pp. 1961-1976.

Grabel, I., "Averting Crisis? Assessing Measures to Manage Financial Integration in Emerging Economies", en Cambridge Journal of Economics, vol. 27, núm. 3, 2003, pp. 317-336. 
Moritz Cruz y Javier Lapa

Leeper, E., "Monetary Science, Fiscal Alchemy", en NBER Working Paper, núm. 16510, 2010, pp. 1-63.

Obstfeld, M., "Models of Currency Crises with Self-fulfilling Features", en European Economic Review, vol. 40, 1996, pp. 1037-1047.

Pérez, E. y Vernengo, M., "How Stimulative has been Fiscal Policy Around the World”, en Challenge, vol. 53, num. 3, 2010, pp. 6-31.

Wray, R. "Endogenous Money: Structuralist and Horizontalist", en Levy Institute Working Paper Series, num. 178, 2007, pp. 1-32. 